\title{
Em dois tempos: a crítica de autoria negra no início e na atualidade da literatura brasileira
}

\author{
Nayara Batista da Cruz ${ }^{\mathrm{i}}$
}

\begin{abstract}
RESUMO
Com o advento das lutas do Movimento Negro, o apagamento das narrativas e identidades negras começa a perder estabilidade. A partir desse contexto, o presente artigo tem por objetivo discutir a crítica nacional de dois autores-críticos negrobrasileiros, Machado de Assis e Conceição Evaristo. Para isso, foram selecionados seus respectivos textos, "Notícia da atual literatura brasileira" (1873) e "Gênero e Etnia" (2005), estudados com base na comparação com suas produções literárias. A escolha desses autores buscou recuperar exemplos da autoria negra dos séculos XIX e XXI.
\end{abstract}

Palavras-chave: Literatura brasileira; Crítica literária; Produção ficcional; Autoria negra.

\section{RESUMEN}

Con el adviento de las luchas del Movimiento Negro, el borrado de las narrativas e identidades negras empieza a perder estabilidad. A partir de ese contexto, el presente artigo tiene como objetivo discutir la crítica brasileña de dos autores críticos negrobrasileños, Machado de Assis y Conceição Evaristo. Para esto, fueron seleccionados sus respectivos textos, "Notícia da atual literatura brasileira" (1873) y "Gênero e Etnia" (2005), estudiados en base a la comparación con sus producciones literarias. La selección de estos autores buscó recuperar ejemplos de la autoría negra de los siglos XIX y XXI.

Palabras clave: Literatura brasileña; Crítica literaria; Producción ficcional; Autoría negra.

\footnotetext{
i É mestranda em Letras - Literatura Brasileira pela Universidade do Estado do Rio de Janeiro (UERJ) e cursa Especialização em Educação das Relações Étnico-Raciais no Ensino Básico (EREREBÁ) pelo Colégio Pedro II. É Bacharel (2015) e Licenciada (2016) em Letras - Português e Espanhol pela Universidade do Estado do Rio de Janeiro (UERJ) e possui Formação de Professores/Nível Médio (2010) pelo Instituto de Educação Carmela Dutra (IECD). Atualmente, é Professora do Ensino Fundamental Anos Iniciais da Secretaria Municipal de Educação da Prefeitura da Cidade do Rio de Janeiro com experiência em alfabetização. Participa do Grupo de Estudos em literatura de autoria negra (LITAN) do Colégio Pedro II. Tem interesse em Educação Étnico-racial, currículo pós-crítico e Literatura afrobrasileira.

ORCID: https://orcid.org/0000-0002-3943-1356 | nayara.lepel@gmail.com
} 


\section{INTRODUÇÃO}

A crítica literária brasileira é estabelecida a partir do final do século XIX. Se nesse momento inicial ela era incipiente, dada a baixa produção literária nacional e a recente independência política de nosso país, pouco a pouco vai se consolidando e servindo como instrumento de orientação para a própria formação do corpus literário. Em vista disso, cabe entender que alguns literatos não se reservam apenas à atuação na construção de uma tradição literária. Para alguns escritores, ao longo do percurso histórico e literário, a crítica foi experimentada. Essa escrita ambivalente possibilitou a esses intelectuais a formulação de propostas e sugestões que orientaram a conformação da nossa literatura, apontando caminhos para a produção de outros autores, bem como de seu próprio fazer artístico.

Dentro dessa visão mais geral, o presente artigo pretende olhar para uma ramificação específica da tradição crítica brasileira: aquela de autoria negra desenvolvida nos séculos XIX e XXI. Nesse panorama, foram selecionados um autor e uma autora, cada um correspondente a um dos séculos apontados. O primeiro deles, que se insere no final do século XIX, é o célebre fundador da Academia Brasileira de Letras, Machado de Assis. A seleção da segunda autoria coube a uma mulher negra atuante na contemporaneidade que atende pelo nome de Conceição Evaristo. Assim, será possível apreciar dois estágios distanciados da crítica literária brasileira, um inicial e outro mais recente, mais precisamente no momento contemporâneo.

Nesse espectro, este trabalho realizará uma análise da produção crítica de tais autores a partir de seus respectivos textos: "Notícia da atual literatura brasileira: Instinto de Nacionalidade", de 1873, e "Gênero e Etnia: uma escre(vivência) de dupla face", de 2005. A análise desses materiais será confrontada com a produção ficcional, destacando a presença de proposições na escrita desses estudiosos. Para esse engenho, foi selecionada a obra de estreia de Machado de Assis como romancista, Ressurreição (1872), enquanto o conto "Maria" foi escolhido para o exame em Conceição Evaristo.

Dessa maneira, a pergunta que se estabelece é: como se conformou a escrita de autoria negra na formação e consolidação da crítica literária nacional que busca o delineamento da literatura brasileira? Esta pergunta é fundamental para compreender a presença de autores negros na crítica e os aspectos característicos de sua escrita 
propositiva e ficcional. A hipótese é que a ficção desses autores trará elementos que dialogam com crítica empenhada por eles.

\section{UM MARCO INICIAL: A CRÍTICA E O ROMANCE DE MACHADO DE ASSIS}

A crítica literária brasileira nasce no período do Romantismo, cronologicamente localizado no século XIX. A respeito do seu estabelecimento, precursores e teoria, Antonio Candido (2000) tece importantes apontamentos. Iniciada pelo estrangeiro Ferdinand Denis, a crítica romântica busca embasamento na teoria do nacionalismo literário, que caracteriza a literatura como veículo de transmissão do sentimento de nação. Além da ruptura com Portugal, marcada pelo nacionalismo, Candido (Ibidem) destaca outros dois sentimentos dominantes: o indianismo e o cristianismo. Segundo o teórico, a presença e atuação de Ferdinand Denis foram importantes para o desenvolvimento do modelo romântico no Brasil, distanciando nosso país dos moldes clássicos artísticos. Trata-se, portanto, não só de uma independência política, como também de uma independência literária. Sobre esse aspecto, o historiador da literatura afirma:

\footnotetext{
Desta verdadeira proclamação de independência literária, como se poderia dizer glosando um escritor atual ${ }^{1}$, decorrem, do ponto de vista crítico, certos temas que serão condutores no Romantismo: estabelecimento de uma genealogia literária, análise da capacidade criadora das raças autóctones, aspectos locais como estímulos da inspiração. (Ibidem, p. 288)
}

Desses três temas, há dois que vão ganhar especial destaque na produção literária brasileira da época. Candido menciona que, no contexto nacional, "impunha-se, portanto, segundo os cânones do momento, considerar a raça e o meio" (Ibidem, p. 289). Sobre esse aspecto da literatura romântica brasileira, Machado de Assis (2008), em ensaio crítico, elabora comentários sobre o que ele chama de cor local. "Notícia da atual literatura brasileira", texto originalmente publicado no periódico O Novo Mundo, em 1873, discute a literatura brasileira do fim do século XIX atravessada - ou não, como veremos mais adiante - pela formação da crítica literária contemporânea. 
Essas duas temáticas, raça e meio, aparecem na análise de Machado, atrelandose com aquilo que ele chama de "primeiro traço, certo instinto de nacionalidade" (Ibidem, p. 105) que compõe a literatura brasileira - ainda inexistente naquele período (Ibidem). Busca o crítico, portanto, provar a existência de uma produção literária independente, vestida "com as cores do país" (Ibidem, p. 105), que se distancia de uma literatura de cunho colonial. Por meio dessa reflexão, ele procura responder a seguinte questão: o que é ou o que poderá vir a ser considerado como Literatura Brasileira? É dessa maneira que apresenta um panorama da literatura contemporânea de sua época, considerando, inclusive, a ausência de uma fortuna crítica que oriente a produção local naquele momento.

Ao construir esse quadro, Machado de Assis direciona seu juízo para aquilo que Antonio Candido (2000) mais tarde salientaria em Formação da Literatura Brasileira como nacionalismo literário. Dentro dessa perspectiva, o autor-crítico destaca dois aspectos característicos daquilo que se estabeleceria como uma espécie de tradição brasileira. O primeiro deles o indianismo e o segundo os costumes locais. A respeito da questão do indianismo, o bruxo do Cosme Velho entende não caber a esse tema nem exclusividade de matéria para os escritores nacionais, nem de exclusão. Sobre isso, torna a afirmar:

\begin{abstract}
Compreendendo que não está na vida indiana todo o patrimônio da literatura brasileira, mas apenas um legado, tão brasileiro como universal, não se limitam os nossos escritores a essa só fonte de inspiração. Os costumes civilizados, ou já do tempo colonial, ou já do tempo de hoje, igualmente oferecem à imaginação boa e larga matéria de estudo. Não menos que eles, os convida a natureza americana, cuja magnificência e esplendor naturalmente desafiam a poetas e prosadores. (ASSIS, 2008, p. 109)
\end{abstract}

E acrescenta mais adiante:

\begin{abstract}
Não há dúvida que uma literatura, sobretudo uma literatura nascente, deve principalmente alimentar-se dos assuntos que lhe oferece a sua região; mas não estabeleçamos doutrinas tão absolutas que a empobreçam. $\mathrm{O}$ que se deve exigir do escritor antes de tudo, é certo sentimento íntimo, que o torne homem do seu tempo e do seu país, ainda quando trate de assuntos remotos no tempo e no espaço. (Ibidem, p. 111)
\end{abstract}

De acordo com ambas as passagens, há mais do que uma análise das características da produção literária daquele tempo. Machado de Assis (Ibidem), em 
"Notícia da atual literatura brasileira: Instinto de Nacionalidade", propõe uma alternativa para encaminhar as próximas obras de nossa tradição. Se o próprio estudioso afirma ser a crítica uma forma de corrigir erros e apontar os rumos "para que a literatura saia mais forte e viçosa" (Ibidem, p. 112), é natural verificar esse direcionamento se desvelar na sua própria produção ficcional.

Ao abordar a conformação romanesca, Machado de Assis, ao mesmo passo em que afirma ser comum à literatura apresentar dados locais, aponta que concernente à "análise de paixões e caracteres são muito menos comuns os exemplos que podem satisfazer à crítica” (Ibidem, p. 114). Para ele, o que justifica a baixa ocorrência desse tipo específico de romance é "a nossa índole [que] não nos chama para aí, ou porque seja esta casta de obras ainda incompatível com a nossa adolescência literária” (Ibidem, p. 113).

\begin{abstract}
Isento por esse lado o romance brasileiro, não menos o está de tendências políticas, e geralmente de todas as questões sociais, - o que não digo por fazer elogio, nem ainda censura, mas unicamente para atestar o fato. Esta casta de obras conserva-se aqui no puro domínio de imaginação, desinteressada dos problemas do dia e do século, alheia às crises sociais e filosóficas. Seus principais elementos são, como disse, a pintura dos costumes, a luta das paixões, os quadros da natureza, alguma vez o estudo dos sentimentos e dos caracteres; com esses elementos, que são fecundíssimos, possuímos já uma galeria numerosa e a muitos respeitos notável. (Ibidem, p. 115)
\end{abstract}

O fato do recente florescer de nossas letras só permitir o desenvolvimento da cor local como traço característico da trajetória inicial de nosso fazer estético denotaria certo amadurecimento quando concretizado, o que Assis (Ibidem) chamou de análise de caracteres, ou seja, é pela sua própria produção que o escritor preencherá a lacuna que ele mesmo teria apontado existir.

Numa espécie de contrafluxo, em Ressurreição, seu romance de estreia, publicado em 1872, é possível verificar uma antecipação do que Machado de Assis chamará de romance de caracteres um ano depois em seu texto crítico. Por conta desse tópico observado pelo próprio enquanto crítico literário, Ressurreição estabelecer-se-ia como o ponto fora da curva no Romantismo brasileiro. A esse respeito, o primeiro romance do consagrado autor foge da habitual descrição de costumes e da abordagem indianista românticas, passando à apreciação da análise de caracteres. Por essa característica, a obra apresentará um olhar atento ao comportamento humano. Machado 
de Assis, portanto, ensaia sua primeira tentativa de tratar da natureza humana, não cabendo espaço para a interferência do meio na sua produção ficcional. Em advertência à primeira edição, o bruxo do Cosme Velho já antecipa a intenção do que pretende com a obra:

Minha idéia ao escrever este livro foi pôr em ação aquele pensamento de Shakespeare:

Our doubts are traitors,

And make us lose good we oft might win,

By fearing to attempt.

Não quis fazer romance de costumes; tentei o esboço de uma situação e o contraste de dous caracteres; com esses simples elementos busquei o interesse do livro. A crítica decidirá se a obra corresponde ao intuito, e sobretudo se o operário tem jeito para ela.

É o que lhe peço com o coração nas mãos. (Idem, 1975, p. 61)

Ao citar Shakespeare, ele reafirma a que veio com sua obra de ficção. O ponto central do romance reside no conflito entre as incertezas, incoerências e ambiguidades humanas. A exemplo dessa questão, no início da obra, o romancista já expõe algumas informações sobre o herói da história:

Do seu carácter e espírito melhor se conhecerá lendo estas páginas, e acompanhando o herói por entre as peripécias da singelíssima ação que empreendo narrar. Não se trata aqui de um carácter inteiriço, nem de um espírito lógico e igual a si mesmo; trata-se de um homem complexo, incoerente e caprichoso, em que se reuniam opostos elementos, qualidades exclusivas, e defeitos inconciliáveis.

Duas faces tinha o seu espírito, e conquanto formassem um só rosto, eram todavia diversas entre si, uma natural e espontânea, outra calculada e sistemática. Ambas porém se mesclavam de modo que era difícil discriminálas e defini-las. Naquele homem feito de sinceridade e afetação tudo se confundia e baralhava. Um jornalista do tempo, seu amigo, costumava compará-lo ao escudo de Aquiles, - mescla de estanho e ouro, - "muito menos sólido", acrescentava ele. (Ibidem, p. 64)

Como relata o narrador no fragmento supracitado, Félix possui temperamento desacordado. A personagem é constituída por personalidade dúbia, como uma moeda que possui dois lados diferentes. Todavia, esses dois avessos compõem uma mesma matéria em plena unidade. Esse aspecto psicológico estabelece diálogo direto com o que fora adiantado por Machado de Assis no fim da advertência da primeira edição. Do trecho shakespeareano, a dúvida é o elemento chave para entender os traços que 
compõem a personagem principal do livro. Ao mesmo passo que amava Lívia, esse amor tinha "um gosto amargo, travado de dúvidas e suspeita [...] qualquer cousa bastava para lhe turbar o espírito" (Ibidem, p. 105-6). Tais palavras do narrador lançam quase que uma previsão do que estaria por vir. Uma carta fora o bastante para que Félix rompesse o noivado com a viúva Lívia.

Esses fatos atestam que na ficção machadiana, no caso de Ressurreição, há um prenúncio das ideias apresentadas pelo próprio Machado de Assis em crítica, o exame de caracteres. Seria seu primeiro romance, um desses raros casos de que fala o autor. Contudo Ressurreição poderia ser vista como apenas um ensaio do que mais adiante consolidar-se-á, conferindo, de forma coerente, valor à crítica literária como atitude educativa para o desenvolvimento da literatura brasileira.

\section{UM MARCO ATUAL: CRÍTICA E CONTO EM CONCEIÇÃO EVARISTO}

É sobre o Romantismo que Conceição Evaristo inicia a discussão sobre o papel da mulher negra na literatura brasileira, em "Gênero e etnia: uma escre(vivência) de dupla face" (2005). A crítica, também contista e romancista, a partir da ideia de que "na literatura brasileira a mulher negra não aparece como musa ou heroína romântica" (EVARISTO, 2005, p. 2), apresenta a negação de espaço positivado à figura da mulher negra na trajetória da literatura brasileira.

Analisando casos de representações femininas na literatura, Evaristo entende que as mulheres negras enquanto "heroínas do cotidiano desenvolvem suas batalhas longe de qualquer clamor de glórias" (Ibidem, p. 4). Essas são as primeiras pistas do modelo de criação que orientarão a produção ficcional da escritora. O que fica possível observar diante de tais considerações é que o paradigma feminino para a mulher branca na literatura nacional canônica não corresponde ao mesmo paradigma para a mulher preta. O mesmo acontece na vida diária. Ainda que mulheres brancas enfrentem processos opressivos que gerem uma demanda de reivindicações, a agenda de lutas de mulheres negras diferencia-se, mesmo portando aproximações.

Todas essas questões funcionam como mote para a escrita da autora. Sua produção é permeada pelas questões sociais presentes na vida da população afro- 
brasileira, principalmente no cotidiano de mulheres negras. Fundamentada nesses pontos, fica estabelecida a tensão entre duas frentes para pensar-se a crítica de Conceição Evaristo e, também, a sua criação ficcional: a denúncia dos problemas enfrentados por mulheres negras, como a subalternização, a fome, a objetificação e a violência; e a representação alternativa às narrativas universais, elaborada na perspectiva de agência, que busca os "arquétipos segundo os mitos africanos: nutre, protege, organiza e cria" (TEODORO, 1960, p. 119 apud EVARISTO, 2005, p. 5). Apesar da tensão, essas duas questões não se eliminam, mas cruzam-se, denotando a complexidade dos recortes de gênero e etnia. Esse recorte interseccional demarca toda a produção de Conceição Evaristo. Dessa demarcação fica em evidência um elemento que extrapola a representação literária, já que esta é moldada pelo estigma limitante atribuído à imagem da mulher negra.

Sendo as mulheres negras invibilizadas, não só pelas páginas da história oficial brasileira, mas também pela literatura, e quando se tornam objetos da segunda, na maioria das vezes, surgem ficcionalizadas a partir de estereótipos vários, para as escritoras negras cabem vários cuidados. Assenhoreando-se "da pena", objeto representativo do poder falo-cêntrico branco, as escritoras negras buscam inscrever no corpus literário brasileiro imagens de uma autorepresentação. Surge a fala de um corpo que não é apenas descrito, mas antes de tudo vivido. A escre(vivência) das mulheres negras explicita as aventuras e as desventuras de quem conhece uma dupla condição, que a sociedade teima em querer inferiorizada, mulher e negra. Na escrita busca-se afirmar a duas faces da moeda num um único movimento. (Ibidem, p. 6)

Conforme as palavras da estudiosa, há uma dupla ação no silenciamento de mulheres pretas. A História, expressa por narrativas dominantes, e a Literatura na sua forma canônica correlacionam-se ao produzir efeitos discriminatórios sobre essas mulheres. Contra os estereótipos impostos pelas correntes dominantes, a autorrepresentação rompe os estigmas habituais da literatura e abre caminho para o papel de agência. Agindo, vivem, e viver cabe tanto nas questões pragmáticas da instância do real e, por isso, da autoria, como também na instância do ficcional, da vida que ganham como personagens, narradoras, protagonistas. Mulheres negras, escrevendo poeticamente sobre suas condições reais, colocam em prática o que Conceição Evaristo (2005) chama de escre(vivências). Ela própria atualiza esse termo toda vez que se assenhora da pena (Ibidem, p. 6). 
Em Olhos d'água (2016), seu livro de contos, embora apresente também meninos e homens, a autora reúne uma gama de mulheres. Em vários deles, seus nomes aparecem destacados no título. Aqui, direcionar-se-á especial atenção a um desses contos, intitulado "Maria", publicado, inicialmente em 1991, nos Cadernos Negros volume 14

\begin{abstract}
Maria estava parada há mais de meia hora no ponto de ônibus. Estava cansada de esperar. Se a distância fosse menor, teria ido a pé. Era preciso mesmo ir se acostumando com a caminhada. O preço da passagem estava aumentando tanto! Além do cansaço, a sacola estava pesada. No dia anterior, no domingo, havia tido festa na casa da patroa. Ela levava para casa os restos. [...] Ganhara as frutas e uma gorjeta. [...] A gorjeta chegara numa boa hora. (Idem, 2016, p. 101)
\end{abstract}

Como é possível verificar, já nas primeiras palavras da história identificam-se quase todas as condições nas quais se enquadra a protagonista desse conto: mulher, pobre, empregada doméstica, mãe e líder de família. Esse quadro se circunscreve na tensão do par denúncia-autorrepresentação, como tratada anteriormente. Isso porque, por meio desse trecho, a contista constrói uma descrição que torna possível a captação dos problemas enfrentados pelo coletivo de mulheres pretas no plano do real, dado que mais tarde aparece em "Gênero e etnia" (2005). É a heroína cotidiana que encarna nas histórias.

Na sequência, outra informação completa esse quadro discutido no texto crítico de Conceição Evaristo. Após o episódio do assalto presenciado pela protagonista do conto, um dos passageiros menciona: "Negra safada, vai ver que estava de coleio com os dois" (Ibidem, p. 41, grifo da autora). A partir desse fragmento, fica evidente a questão racial da personagem principal do conto, um dos pontos centrais para sua crítica e de sua escrita.

Seja na sua condição social, de gênero e/ou racial, Maria sente na pele - não qualquer pele - o extremo da marginalização social. Sobre a identidade, é por ela que Conceição Evaristo constrói a sua escrita. Maria - assim como tantas outras "Marias" experimenta a solidão da mulher negra, o autoritarismo, a marginalização e o racismo. É o cruzamento entre o real e a ficção, definido por Evaristo (2005) como escre(vivência). Dessa forma, pode-se pensar que a escrita, de acordo com essa perspectiva, reorganiza a 
linguagem e a representação da mulher negra na literatura enquanto contesta o lugar a ela relegado na história. Sobre isso, Conceição Evaristo afirma:

\begin{abstract}
Retomando a reflexão sobre o fazer literário das mulheres negras, pode-se dizer que os textos femininos negros, para além de um sentido estético, buscam semantizar um outro movimento, aquele que abriga toda as suas lutas. Toma-se o lugar da escrita, como direito, assim como se toma o lugar da vida. (Ibidem, p. 7)
\end{abstract}

Outro par observável diante dessa perspectiva é a escrita-vida. Nessa lógica, é reafirmada a escrita como o lugar de ressignificação da mulher negra na literatura brasileira. Essa ressignificação comporta o texto como objeto estético, além de retratar, de refletir, ou, em palavras melhores, funcionar como um repositório dos enfrentamentos que mulheres encaram diariamente. Nesse sentido, pela escre(vivência), se coloca as experiências coletivas que produzem o desencadeamento do reconhecimento de situações, atitudes e protagonismos, longe da marca de individualidade, embora não se busque anular nenhuma e qualquer subjetividade.

Se existe a combinação entre escrita e vida, a dor é um elemento presente no fazer literário de Conceição Evaristo enquanto mulher. Seja a dor física, trivial ou grave, seja a dor simbólica. Isso se comprova no seguinte trecho: "A palma de uma de suas mãos doía. Tinha sofrido um corte, bem no meio, enquanto cortava o pernil para a patroa. Que coisa! Faca a laser corta até a vida!” (Idem, 2016, p. 40). Esse fragmento é significativo por mais de uma razão. Ele expõe uma dor física resultante de um trabalho e essa exposição ganha ênfase na hipérbole "Faca a laser corta até a vida!" (Ibidem, p. 40). Essa frase é repetida outras duas vezes. Na última vez que ela aparece, a frase é reformulada. Após Maria ser linchada, a história segue seu fluxo e permite a sua reapresentação, como é possível verificar no enxerto a seguir que relata esse episódio emblemático:

Tudo foi tão rápido, tão breve, Maria tinha saudades de seu ex-homem. Por que estavam fazendo isso com ela? O homem havia segredado um abraço, um beijo, um carinho no filho. Ela precisava chegar em casa para transmitir o recado. Estavam todos armados com facas a laser que cortam até a vida. Quando o ônibus esvaziou, quando chegou a polícia, o corpo da mulher estava todo dilacerado, todo pisoteado. (Ibidem, p. 42, grifos nossos) 
Nesse fragmento, a hipérbole deu lugar à metáfora. Por esse deslocamento de sentido, a faca a laser (em seu sentido literal) que corta até a vida (sentido figurado) não é mais faca (agora figurado), mas corta a vida (literal). A forma como a escritora manipula a linguagem alterna a ordem semântica dos elementos, criando a experiência de (quase) morte. Essa é uma exemplificação do entrelaçamento dos sentidos estético e experiencial da escrita negro-feminina apontado pela escritora.

Conceição Evaristo é a própria mulher deflagrada na sua crítica. Mulher que toma o lugar da escrita para praticar a escre(vivência), assumindo e retratando o ser mulher e o ser negra. No jogo entre o real e a ficção, discutido na sua crítica, a coesão é estabelecida por duas vias: no plano estético e no plano produtor.

\section{CONSIDERAÇÕES FINAIS}

Ocupou-se, aqui neste estudo, em tratar de um pequeno recorte da produção crítica de escritores negros, dentro da tradição crítica literária brasileira, relacionando suas proposições teóricas ao seu fazer literário. Dessa maneira, o intuito era apontar a presença, ou não, de conceitos discutidos criticamente na produção estética. Para cumprir esse intuito, elegeu-se dois representantes, um homem e uma mulher. $\mathrm{O}$ primeiro, Machado de Assis, inserido no encerramento do século XIX. A segunda foi Conceição Evaristo, mulher atuante na contemporaneidade.

De Machado, trabalhou-se o seu ensaio crítico "Notícia da atual literatura brasileira: Instinto de Nacionalidade", publicado em 1873. A partir disso, foi possível verificar como a literatura nacional da época se encaminhava e, principalmente, o desejo de apreciar romances de análise de caracteres. Em seguida, confrontando sua leitura crítica com seu romance Ressurreição, de 1872, empreendeu-se a análise de elementos que o configuram como romance de caracteres. Essa obra romanesca precede as orientações apontadas por seu autor um ano mais tarde.

Ao deslocar-se, numa linha do tempo, do século XIX para o século atual, chegase a Conceição Evaristo. Com a publicação de "Gênero e Etnia: uma escre(vivência) de dupla face", em 2005, destaca-se o conceito de escre(vivência) dado pela autora. A ideia de autorrepresentação da mulher negra pelas suas experiências é resgatada, neste 
trabalho, na apresentação de "Maria", conto presente no livro Olhos d'água (2016), publicado originalmente em 1991.

Em Machado de Assis há uma reafirmação de proposições concretizadas antecipadamente em seu romance Ressurreição, o que firma uma linearidade entre a sua dupla atuação. Algo similar acontece com a escrita de Conceição Evaristo. Sua produção crítica recupera elementos da sua escrita ficcional. A concepção de ideias que são elaboradas cuidadosamente anos depois também aponta para uma aproximação entre crítica e ficção na autora.

Em síntese, pode-se afirmar uma coerência dos dois literatos analisados no que se refere ao diálogo entre suas produções ficcional e crítica. Ademais, é possível afirmar que, em momentos históricos distanciados, a representação negra figura na construção da crítica literária brasileira. Estabelecendo-se como um dos precursores do trajeto crítico-literário brasileiro, Machado de Assis avalia o quadro literário de seu tempo, traçando orientação para os próximos passos de amadurecimento da literatura nacional, nesse período de formação. No que tange à fase atual, a crítica de autoria negra, com base nas considerações de Conceição Evaristo, vem-se conformando pela reivindicação da autorrepresentação da mulher negra, indicando uma renovação estética.

\section{Referências}

ASSIS, Machado de. O ideal do crítico. Organização de Miguel Sanches Neto. Rio de Janeiro: José Olympio, 2008.

Ressurreição. Edições críticas de obras de Machado de Assis, v. 8. Rio de janeiro: Civilização Brasileira, 1975.

CANDIDO, Antonio. Formação da Literatura Brasileira. Belo Horizonte: Itatiaia, 2000.

EVARISTO, Conceição. Gênero e etnia: uma escre(vivência) de dupla face. In: MOREIRA, Nadilza M. de Barros; SCHNEIDER, Liane (Org.). Mulheres no mundo: etnia, marginalidade, diáspora. João Pessoa: Idéia/Editora Universitária, 2005.

2016.

Maria. Olhos d'água. Rio de Janeiro: Pallas/Fundação Biblioteca Nacional, 
Em dois tempos: a crítica de autoria negra no início e na atualidade da literatura brasileira

Recebido em: 12/01/2021

Aceito em: 12/04/2021

${ }^{1}$ Antonio Candido faz referência a Jamil Almansur Haddad. (2000, p. 288) 